OPEN ACCESS

Edited by:

Nandita Biswas Mellamphy, University of Western Ontario, Canada

Reviewed by:

Yi-Tung Chang,

National Pingtung University, Taiwan

Mattias Kärrholm,

Lund University, Sweden

*Correspondence:

Katerina Kolozova

katerinakolozova@gmail.com;

katerina.kolozova@isshs.edu.mk

Specialty section:

This article was submitted to

Sociological Theory,

a section of the journal

Frontiers in Sociology

Received: 29 January 2018

Accepted: 17 August 2018

Published: 06 September 2018

Citation:

Kolozova K (2018) Philosophical and Speculative Economies of the

Vanishing Body. Front. Sociol. 3:26.

doi: $10.3389 /$ fsoc. 2018.00026

\section{Philosophical and Speculative Economies of the Vanishing Body}

\author{
Katerina Kolozova* \\ Institute of Social Sciences and Humanities, Skopje, Macedonia
}

The human is materially determined by that "irrational" hybrid of the physical and machine resulting in no more and no less sense than the "pure body" (if such thing is possible beyond mere postulation) is endowed with. The "rational" part of it or the "agency of making sense" remains outside the materiality of either the body or the machine-it is the automaton of signification or language. The automaton of capital and philosophy is individually substantiated as "subjectivity," and more specifically that of the split capitalist self. The hybrid consisted of the physical (natural and machinic), on the one hand, and of the subject of signification, on the other hand, is the monstrosity that ultimately escapes sense: it is inhuman (Haraway) or non-human (Laruelle). It is that inhuman inanity that is neither subject nor merely body nor just a machine, the non-human. Similarly to Donna Haraway's claim about the radical constructedness of the human as cyborg (Haraway, 1991: 149-181), Marx argued that sociality, which includes both economic production and the so-called social reproduction (via the means of production), on the one hand and physicality on the other hand constitute the species-being of humanity. The human is radically constructed, yet, in the last instance, determined by the physical, argue both Haraway and Marx.

Keywords: Marxist-feminist theory, post-humanism, non-philosophy, speculative realism, Luce Irigaray

\section{INTRODUCTION: MARX'S AND LARUELLE'S POST-PHILOSOPHY AND ITS RELEVANCE FOR THE CONSIDERATIONS OF THE POSTHUMAN}

In order to circumvent the possibility of a conversation of the post-human to turn into a transhumanist phantasm, I propose that we radicalize the concept of the human. The procedure of radicalization, as conceived within Laruelle's methodology of non-standard philosophy, consists in arriving at a concept whose determination in the last instance is the real. It is homologous to Marx's notion of the determination in the last instance which is material. Both Marx and Laruelle, however, avoid the concept of "the material" as overly philosophical—or as an inverted version of idealism as Marx explains in his Critique of Hegel's Philosophy in General-and resort to the notion of the real. In addition to the real, Marx speaks of the physical and the sensuous. When speaking of the human instantiations of the real Laruelle equates the real with the concept of "the lived" (le vécu), also avoiding philosophical materialism, or more specifically dialectical-materialism. He too declares materialism to be philosophically indebted and moreover inextricable from philosophy (Laruelle, 2014). Both Marx and Laruelle demand an exit from philosophy: a science of humanity that operates with "philosophical [conceptual] material."

Their respective projects of non-philosophy or post-philosophy (or "an exit from philosophy" as Marx puts it) are both committed to radical humanism, as if the one is impossible without the 
other. And it seems that it is (impossible): in order to understand humanity in its last instance, as one among the endless forms of reality that can become subject to formal investigation, one ought to adopt a scientific stance rather than philosophical. The latter is defined by the concept or thought submitting to the real rather than the other way around (Laruelle, 1989). The opposite way is what in turn defines philosophy, according to both Marx and Laruelle. The Human of the post-theological thought is predicated upon the principle of philosophical sufficiency or thought's autoreferentiality (Laruelle, 1989). If we are to think the post-human we ought to resort to radicalization of the notion of the human in order to achieve its "philosophical impoverishment" (Laruelle, 2014: 2) and, in that way, circumvent the problem of anthropocentrism. Philosophical humanism is anthropocentric and, if we are to invent radically novel ways of thinking the post-human, it is necessary to evacuate from the notion of "the post-human" not only the principle of human sufficiency but also that of philosophical sufficiency.

Only by arriving at the identity in the last instance of the human, determined by an instance of the real (and material), we can conceive of a thought that is not imbued with anthropocentric mythology and teleology. We shall call the human of non-philosophy a non-human. In that way we are achieving greater proximity to Haraway's notion of the cyborg as inhuman. One of the mechanisms to achieve this goal is also to move beyond the subject-centered discourse of critical theory, radicalize and fully formalize the two categories that constitute the dyad of the non-human: physicality and the signifying automaton. Moving beyond the human morphology that shapes the post-structuralist notion of the Subject, we shall investigate the dyad the cyborg or the (non-)human in the last instance isradical and impossible to be unified or reduced to a single truth or to that philosophically determined amphibology truth-real or the Being (tò õn).

\section{POST-PHILOSOPHICAL MATERIALISM OR NON-MATERIALISM AND THE POST-HUMAN}

According to non-philosophy, the real and what thinks it are unilaterally positioned. The real remains in the last instance meaningless, yet its effects can be cloned into thought while thought and the real are not reducible to one another. Philosophy, on the other hand, seeks to reconcile the senseless real with the truth by way of transforming it into truth, or hybridizing truth and the real into "the being," a philosophical entity determined in the last instance by thought rather than the real. Capitalism acts in an analogous way: materiality is mere material for the creation of values whose first form is commodity. At the end of the process, to quote Marx, we are faced with the following reality: "The value of commodities is the very opposite of the coarse materiality of their substance, not an atom of matter enters into its composition." (Marx, 1887) The worker who alienates his or her labor for wage divorces it from its "coarse materiality." It is an alienation through a second and circular or philosophical gesture whereby precisely the radically heterogeneous self is alienated from itself: instead of being affirmed, the grounding heterogeneity is canceled by substituting the senseless real it is with a meaning, truth to which it is reduced. The wage worker is alienated from the process of production, and reinstituted as (abstract) "labor" or "service" void of selfhood and materiality.

[...] the worker becomes ever more exclusively dependent on labor, and on a particular, very one-sided, machine-like labor at that. Just as he is thus depressed spiritually and physically to the condition of a machine and from being a man becomes an abstract activity and a belly, so he also becomes ever more dependent on every fluctuation in market price (Marx, 1959).

By becoming "an abstract activity and a belly", the worker "becomes ever more dependent on every fluctuation of market price." The workings of abstraction-as a procedure of ontology with direct political consequences-produce a split self that is exposed to merciless exploitation. The abstraction at issue and as problematized by Marx is a philosophical postulation of reality based on the cancelation of the real by way of its substituting with "thought" or "idea." Thus, we are not problematizing the relevance of the cognitive faculty called abstraction but the modes of its ontologization that are fundamentally ideological. A derealized abstraction or one exempt from materiality yet seeking to instill itself as the only relevant reality, the "abstraction of thought" that cancels the real and acts in its stead, is the object of Marxist political-economic, philosophical and epistemological critique, argues Sohh-Rethel. So, he invites us to conceive of a materially determined abstraction he calls "real abstraction":

Forms of thought and forms of society have one thing in common. They are both "forms." The Marxian mode of thought is characterized by a conception of form which distinguishes it from all other schools of thinking. It derives from Hegel, but this only so as to deviate from him again. For Marx, form is time-bound. It originates, dies, and changes within time (Sohn-Rethel, 1978: 17).

The cognitive capacity belongs to the realm of thought but its effects in the reality belong to the realm of the real and the material. The chasm between the real and thought is never bridged, claims Sohn-Rethel in his project of Marxist epistemology, and the materialist science does not care to do so. It is indifferent to a goal of that sort:

[...] the historical materialist stands in irreconcilable opposition to all traditional, theoretical philosophy. For this entire tradition it is an established fact that abstraction is the inherent activity and the exclusive privilege of thought; to speak of abstraction in any other sense is regarded as irresponsible, unless of course one uses the word merely metaphorically. But to acquiesce in this philosophical tradition would preclude the realization of the postulate of historical materialism. If the formation of the consciousness, by the procedure of abstraction, is exclusively a matter for the consciousness itself, then a chasm opens up between the forms of consciousness on the one side and its alleged determination in being on the other. The historical materialist would deny in theory the existence of this chasm, but in practice 
has no solution to offer, none at any rate that would bridge the chasm (Sohn-Rethel, 1978: 18).

This is so because the reconciliation between "consciousness" (thought) and the real that determines it would be a philosophical concern. Science seeks to describe and explain the operations of reality without concerning itself with questions of metaphysics. Sohn-Rethel's Marxist science and Laruelle's non-Marxism, and for that matter non-philosophy too, have an identical treatment of the "chasm" at issue. The affirmation of the unilaterality of its two elements is what the radical dyad relies on. Such is the dyad at the heart of the non-human, the one consisted of the real of materiality made of machine and body, on the one hand, and language or subjectivity, on the other hand. Haraway's post-human or inhuman metaphorically called "the cyborg" is a similar kind of a radical dyad. Radical, thus, in all three instances of a dyad-the non-human, the post-human and the species being of humanity-refers to the absence of reconciliation of the "chasm" Sohn-Rethel writes of. Yet again all of them are in the last instance determined by the real of this chasm and its materiality. In fact, the chasm itself is nothing more than materiality: there is no truth which gives sense to it, reduces it to a purpose or even just meaning. It is a vulgar and senseless real, a monster constituted by an animal, machine and "subjectivity" or the instance of "making sense," the automaton of language (whose hardware, as already made clear, can be both organically and synthetically produced).

Instead of affirming the "radical dyad" thus presented, the alienated capitalist subject is detached and self-exploitative toward the heterogeneous kernel of the non-human. The exploitation of the non-human in its last instance is occasioned by the exploitation of the physical insofar as "resource." The materialistic stance of the capitalist subject, embodied by both the worker (who trades labor for wage) and the capitalist, is marked by an anorexic treatment of the physical. Namely, the material is indeed the only thing that can make the capitalist subjectivity happy. However, immersing into it without restraint or allowing to be devoured through pleasure (or by pain) renders the material meaningless-"mere matter." The less transcendental (or transposed to representation) the more "vulgar" the material is. In other words, the closer to its determination in the last instance, i.e., to the real, the less philosophical or transcendentally minimal, the more repulsive. Capitalist subjectivity desires the material which has abrogated itself, canceled itself insofar as the vulgar real, and has, therefore, installed, through its self-negation, its speculatively produced image as "the more perfect form of reality" than that of the "mere real."

I subscribe to Lacan's and Laruelle's understanding of the real as the effect or modality of reality manifested as trauma or tuché (Lacan, 1998: 52). The term tuché comes from the ancient Greek word meaning both "accident" and "encounter." The real "takes place" only in the form of a thrust into and a disruption of the signifying chain. In short, the real is the exteriority to thought, "the out there" to human subjectivity determined in the last instance by language. It is unruly; it lacks form and meaning. It is an unexpected, elemental intervention of "what makes no sense" into the/a universe of sense and meaning, i.e., "the world" in Laruellian sense. Making sense out of its effects is operating with re-presentation (of the real), not with the real itself. Thus, although the workings of thought create effects of the real, when they assume the status of the real, they make no sense and are as elemental as "the vulgar real" of nature.

Although nature is a reality that can be technically reproduced and intervened upon, it is first and foremost a radical exteriority to thought, regardless of whether we are dealing with "nature proper," or with its synthetic technological re-production. The pretension of thought to act in the stead of the real, and in particular of nature, is essentially philosophical and speculative. Therefore, the invasion and subjugation of the physical and the organic, regardless whether naturally or synthetically produced, carried out by (human) Reason is analogous to the mind's oppressive and exploitative control and subjugation of the body, one based on the old Greek, Christian, and Cartesian dichotomy and hierarchy between body and mind. Marx proposes complete reversal of the hierarchy:

Here we see how consistent naturalism or humanism is distinct
from both idealism and materialism, and constitutes at the same
time the unifying truth of both. We see also how only naturalism
is capable of comprehending the action of world history. Man is
directly a natural being. As a natural being and as a living natural
being he is on the one hand endowed with natural powers, vital
powers-he is an active natural being. These forces exist in him
as tendencies and abilities-as instincts. On the other hand, as
a natural, corporeal, sensuous objective being he is a suffering,
conditioned and limited creature, like animals and plants (Marx,
1959).

Nature, the physical, and the sensuous-all three are terms used by Marx that correspond with Donna Haraway's "organic"-are the real in the last instance since they are determined by their being outside of what makes sense, by their being the thrust of tuché into the automaton of signification. Concepts can also assume the status of the real if they act as an exteriority by virtue of producing material conditions for the thinking subject that seeks to grasp them. This point is thoroughly elaborated by Sohn-Rethel referenced above 1978. When adopting a materialist position, aligned with Marx's non-philosophical understanding of it, one necessarily makes a metaphysical choice of assigning a different status to the material within the frame of the given dichotomy. Following Laruelle, one can dismantle the dichotomy itself as essentially philosophical and argue for "dualysis" (Laruelle, 1989: 93-95) whereby thought and the real are seen in their unilaterality as radically distinct categories. The realist (and materialist) thought succumbs to the authority of the real, rather than to the always already auto-referential universe of philosophy.

A truly materialist thought will not be moved by the pretension to fully subjugate the body, but will rather respond to the body's effects of resistance toward such a pretension. It would be determined in the last instance by "the thrust of irrationality," i.e., by the mere physical effects, or the pure trauma the real is, upon the translucence of sense capitalist bourgeois society consists of. The inferior position of the body in the 
body-mind hierarchy is what enables the capitalist exploitation of lives in the name of an abstraction. It is for this reason that a communist revolution to overthrow capitalism entails a process of coming to terms with some metaphysical presuppositions, those that preserve the superior, masterful, and exploitative position of mind or "the Idea." Such choice is political, but also one determined by a realist epistemic stance that is essentially non-philosophical both in the Marxian and Laruellian sense. In the last instance, realist thought succumbs to the authority of the real rather than to a philosophical system.

Nature, the organic, and the bodily, as the exteriority par excellence with regard to thought to which it is manifested as trauma, is what the realist, materialist, and Marxian thought succumbs to in the last instance. It succumbs to the "diktat of the real" (Laruelle, 2014: 67) rather than to a philosophy or to a political program which, devoid from the effect of the real/the determination in the last instance, is the same as philosophy. The ambition to surreptitiously replace the unruly reality (of nature) with a speculative universe which pretends to be the real will inevitably be undercut by a thrust of "what makes no sense," caused by either "ecological catastrophes," by the trauma of the lived, or of the real as embodied pain that the human in the last instance is (i.e., by the revolting victim). The "out there" that is presumably material is always already "nature." According to Anthony Paul Smith, thought necessarily presupposes nature as its cognitive regulatory and organizational principle, nature is one of "the first names of the real" (Smith, 2013: 15). The only real we, the humans and our subjectivities, encounter is that which comes from the physical world. The generic form of transcendental transposition of the realm of the encountered physical "out-there" is the concept of "nature" in its commonsensical manifestation. The manifestation in question is very similar to the Sellarsian "manifest image" of reality that necessarily results into philosophical spontaneity (Sellars, 1963: 6-8). Philosophy and all humanism, including the post-humanist project of technological progress, depart from the concept of nature that in its last instance remains a "manifest image of reality" or one unchecked for its "spontaneous philosophical faith" (Laruelle, 1989: 27). A non-philosophical treatment of nature departs from a procedure of transcendental impoverishment of the concept, arriving to an identity in the last instance of what is referred to as "nature." The real determining the identity in the last instance or its clone is the physical exteriority (Laruelle, 2016: 10, 17-24, 39). Nature, however, insofar as philosophical concept will continue to contain aspects of meaning that are purely transcendental and determined by the philosophical chôra, defined in opposition or correlation to other philosophical concepts such as rationality, idea, mind, human or divine reason. Such meaning of the concept makes sense only inside of philosophy whereas insofar as a post-philosophical clone of the real it remains determined as "physical exteriority," and its relation to reason or senselessness does not play a role.

The classical, most authoritative, and most enduring philosophical postulation of nature is the one that has produced the hierarchy between the physical (material) and the mind (idea), while simultaneously declaring it (the hierarchy) the foundation of any viable philosophy about either of the components of the binary. According to this hierarchy, from Aristotle to Descartes, and from the Enlightenment to the twenty-first century ideas of sciences and morals, matter or nature is the inferior term in the hierarchy. Within the frame of this binary, inferiority seems to function as an invitation to exploitation and subjugation. Hence, nowadays, we, the subjects of twenty-first century global capitalism, rarely speak of nature (except in romantic and recreational idioms), but rather of "natural resources" (and ecology whose primary goal is to provide "sustainability" of these resources). When the authoritative discourses of politics and science refer to nature in the second decade of the twenty-first century, they invoke a speculative entity that perpetuates exploitation in the name of the absolute speculation-contemporary capitalism.

\footnotetext{
No, nature is not veiled, but thinking this allows our regional knowledges to think that they can unveil nature, that they can touch and circumscribe nature with thought and thereby either exploit her for our own gain or save her. Our contemporary climate, both in the physical and intellectual sense, is determined by a single force: the neoliberal capitalist ideology that demands everything reduce its value to the quantitative measure of money so that it can produce more of this measure. Nature, though, appears to be purposely deviating from what is accepted as good, proper, or reasonable in capitalist society. Nature itself appears to be refusing to go away, to separate itself off from "culture" and the human person, and insists on inhering to every part of culture and within every human person, and it resists bowing before capitalism's demand, to be measured as something relative rather than the radical condition for any relative measurement (Smith, 2013: 14-15).
}

Exploitation specific to the capitalist mode of production is made possible by the procedure of alienating nature or the "physical" (Marx)-or, in philosophical terms, "the material"-through speculation which renders it nothing more than a "resource" of "economic growth." This procedure of reduction is considered to serve the highest purpose of the totality of human activity in the universe of capitalism - to constitute "the material" out of which commodities are being produced which operate in the abstract world of surplus value, i.e., money. The goal of communism is the opposite. Namely, it is about establishing complete unity of man with nature, says Marx.

The human aspect of nature exists only for social man; for only then does nature exist for him as a bond with man-as his existence for the other and the other's existence for him-and as the life-element of human reality. Only then does nature exist as the foundation of his own human existence. Only here has what is to him his natural existence become his human existence, and nature become man for him (Marx, 1959).

However, it is the "human aspect" of nature which "exists only for social man," and not the nature in itself or "per se" that one establishes unity with. The human aspect of nature is lived by "the social man" in the form of a "bond with men." In this sense, nature is not an object of scientific thought. Rather it is the material ("physical and sensuous") existence that serves as such object. "Nature," as demonstrated, is yet another philosophical 
creation. Alienation from oneself is alienation from the physical ("natural") bond with fellow "social men." Communism seeks to restore the sense of immediacy, the physicality of this bond, by turning abstraction into the "lived" or "the real thought succumbs to," putting it in Laruellian terms $(2015,67)$.

\section{FEMINISM, SOCIALISM AND THE QUESTION OF TECHNOLOGY}

The machine or automation as an independent, self-enveloped and self-sufficient universe of signification or value-production is what constitutes "capitalism out of joint." Value is produced out of value, sign out of sign, according to the laws of language as postulated by De Saussure. Language constitutes a self-sufficient universe. Capitalist market constitutes yet another exchange system of language. Unlike the "natural languages" that do not seek to cancel the diktat of the real and physicality they submit to in the last instance, the capitalist signifying chain perpetually engages in transforming the real into a resource for signification.

The development of the means of labor into machinery is not an accidental moment of capital, but is rather the historical reshaping of the traditional, inherited means of labor into a form adequate to capital. The accumulation of knowledge and of skill, of the general productive forces of the social brain, is thus absorbed into capital, as opposed to labor, and hence appears as an attribute of capital (Marx, 1973: 622).

Machinic automation is capitalist creation of surplus value taking on a life of its own. It is the endless chatter of signifying production (or production of value tout court), in a schizophrenic split from the material in the last instance. The material is always already indifferent to any attempts of the signifying intentionality to reproduce and "perfect" it. The capitalist exploitative relation to it intends to be indifferent, unilateral while, in fact, remaining relational as it has to posit the "physical" as "mere material." The metaphysical anxiety springing from the fact that a postulation is not the same as the real is soothed with a classical philosophical move: the postulate itself is accorded the status of the real. Its latest authoritative mutation is that of constructivism which annuls the real as irrelevant, as sheer "noise," as non-existent insofar it is outside the human reach of comprehension and manipulation.

Some of the most influential feminist Marxist philosophers have advocated technological progress as the main avenue of women's liberation. Shulamith Firestone claimed that social subjugation of women is the result of their biological vulnerability (Firestone, 1970: 10). Donna Haraway has argued that the exploitation of the animal is the cornerstone of capitalism, and that the feminist-socialist emancipation must go through the liberation of the physical. According to Haraway, technology is the creation and property of militaristic and capitalist patriarchy establishing a hierarchical binary with the biological or the animal whereby the latter is subjected to and exploited by the former (Haraway, 1991: 151). To liberate the animal, therefore, implies to liberate the physical and, hence, to liberate women from their biological vulnerability. Rosi Braidotti has advocated the thesis about animal-machine continuity in her Metamorphoses (Braidotti, 2002: 117-171) only to build on it the materialist defense of life (zoe) from capitalist commodification and exploitation elaborated in The Post-human (Braidotti, 2013: 62).

A continuity between the physical and the technological constituting what Haraway terms "the cyborg" is the form of subjectivation endowed with the potential for socialist and feminist liberation. The first condition for the appearance of the cyborg, Haraway argues, is the hybridization of the animal and technology, resulting into "bestiality" as its underpinning quality:

And many people no longer feel the need for such a separation; indeed, many branches of feminist culture affirm the pleasure of connection of human and other living creatures. Movements for animal rights are not irrational denials of human uniqueness; they are a clear-sighted recognition of connection across the discredited breach of nature and culture. The cyborg appears in myth precisely where the boundary between human and animal is transgressed. Far from signaling a walling off of people from other living beings, cyborgs signal distrurbingly and pleasurably tight coupling. Bestiality has a new status in this cycle of marriage exchange (Haraway, 1991: 152).

Bestiality means both animality and monstrosity, and the cyborg is a monstrous figure preconditioned by a politics firmly asserting continuity between nature and culture, body (or the organic) and technology, animal and human, argues Haraway (1991: 150, 155).

\begin{abstract}
No longer structured by the polarity of public and private, the cyborg defines a technological polls based partly on a revolution of social relations in the oikos, the household. Nature and culture are reworked; the one can no longer be the resource for appropriation or incorporation by the other (Haraway, 1991: 150).
\end{abstract}

A new politics that is profoundly feminist and socialist, a "cyborg politics" according to Haraway, ought to emerge from the hybrid subjectivities made possible precisely by the affirmation of the defining continuities between the animal and machine.

Cyborg politics is the struggle for language and the struggle against perfect communication, against the one code that translates all meaning perfectly, the central dogma of phallogocentrism. That is why cyborg politics insist on noise and advocate pollution, rejoicing in the illegitimate fusions of animal and machine (Haraway, 1991: 176).

The prerequisite of Haraway's, Braidotti's, and Firestone's projects of a feminist materialist and socialist revolution through technology, is, let us underscore, the emancipation of the body from the brutal exploitation on the side of-what obviously comes down to-(Hegel's) Spirit: a rational idea which sees the natural or the physical as mere material to serve a "superior purpose." The element that is postulated as superior in the philosophical-capitalist binary is, of course, thought, mind or the idea. The defining capitalist and/or philosophical dualism 
dictates that rationality is more than a mere cognitive facultyit is the main constituent of its own ontology insofar rationality is in and for itself the "purpose."

If we are to pursue a feminist-socialist project established in fidelity with Marx's oeuvre, we should overcome the founding contradiction of capitalism consisting in the split between "abstract activity and a belly." The brutal indifference of "abstraction" vis-à-vis the "belly" creates an unsustainable division that will inevitably be materialized or realized as revolt. And it will be the revolt of the suffering bodies, always already preceding that of "philosophical indignation." Regardless of the outcomes of such (imagined) revolt, the very logic of capitalism will not only be undermined, but also canceled; it will consist in rendering meaningless or disabling the very possibility of the cruelty specific to capitalism-the full rationalization of any suffering of the body producing self-exploiting subjects or commodities.

Sexuality and reproduction are central coordinates of bodily experiences. That is why I do not see the possibility of feminist emancipation in the capacity of technology to amputate sexuality and reproduction from the female body. A properly Marxian vision of technology's feminist emancipating force would consist in arguing for its prosthetic function. Instead of assigning it an ontological status, a Marxist feminist vision views technology as a social function of prosthesis to the human body and practice. We should understand the term "prosthesis" in its etymological sense referring to its status of extension with respect to the physical rather than substitute or ontological perfection (as in "a nature more perfect than nature itself"). Instead of relying on the philosophical interpretations of technology which are unavoidably determined by the hierarchical oscillations between "reason" and "body," a Marxist understanding of technology should operate with its prephilosophical meaning of techné and, therefore, its prosthetic essence. Anchoring technology in the real and in the physical is in direct opposition to the self-sufficient universe of the automation defining of capitalism, both as metaphysics and as economy. The prosthetic function of feminist and communist technology will serve the liberation of the female body from pain, from the physical suffering specific to the female sex, and increase the potentiality of its active participation in social reproduction.

At this point of technological development and accelerationist euphoria, Firestone's warning that technology does not possess

\section{REFERENCES}

Braidotti, R. (2002). Metamorphoses: Toward a Materialist Theory of Becoming. Cambridge: Polity Press.

Braidotti, R. (2013). The Posthuman. Cambridge: Polity Press.

Firestone, S. (1970). The Dialectic of Sex: The Case for Feminist Revolution. New York, NY: William Morrow and Co.

Haraway, D. (1991). Simians, Cyborgs and Women: The Reinvention of Nature. New York, NY: Routledge.

Lacan, J. (1998). The Seminar of Jacques Lacan, Book XI: The Four Fundamental Concepts of Psychoanalysis, ed J.-A. Miller, trans. immanent emancipatory tendencies, but can rather be used against women and children, seems urgent to consider:

Though the sex class system may have originated in fundamental biological conditions, this does not guarantee once the biological basis of their oppression has been swept away that women and children will be freed. On the contrary, the new technology, especially fertility control, may be used against them to reinforce the entrenched system of exploitation (Firestone, 1970: 10).

What technology does, and how it does it, affects the entire society and makes it subject to debate that belongs to the field of political struggle. The idea that science and technology possess some inherent laws of functioning and self-regulation that are independent of the ruling ideology in a society resembles the (neo)liberal naïve belief that the capitalist economy is based on laws that constitute a nature in its own right (or that it emulates nature itself). It is for this reason that economics and technological science of authority should be able to convey and problematize their politico-metaphysical presuppositions. Conceptualized in line with these parameters, technology or the proponents of infinite technological progress should be able to account for its social consequences and set its political and economic goals. The metaphysical presupposition that technology's development moves along a curve of innate infinity intimates not only the "principle of sufficient philosophy" according to Laruelle (as explained above) but theological reason as well. It is the product of the perennial philosophicotheological opposition between the immortality of reason and finitude of nature and physicality. If we are to establish a socialist and feminist critique of the contemporary project of technological development, moving beyond this type of metaphysics and also beyond philosophy is to be considered its unavoidable grounding gesture. The non-humanist human or the non-human constituted of the machine-body continuity and the signifying automaton affirmed in its brutal and senseless reality escapes philosophy and allows for a historical-materialist conceptualization of technology and its role in the constitution of the post-humanist self.

\section{AUTHOR CONTRIBUTIONS}

The author confirms being the sole contributor of this work and approved it for publication. by A. Sheridan (New York, NY; London: W. W. Norton and Company).

Laruelle, F. (1989). Philosophie et non-philosophie. Liège: Pierre Mardaga.

Laruelle, F. (2014). Introduction to Non-Marxism. Trans. by Anthony Paul Smith. Minneapolis, MN: University of Minnesota Press-Univocal Publishing.

Laruelle, F. (2016). Theory of Identities. New York, NY: Columbia University Press.

Marx, K. (1887). Capital: Volume I. Translated by S. Moore and E. Aveling, ed F. Engels (Moscow: Progress Publishing), Available online at: https://www. marxists.org/archive/marx/works/1867-c1/ 
Marx, K. (1959). Economic and Philosophical Manuscripts 1844. Moscow: Progress Publishers. Available online at: https://www.marxists.org/archive/marx/works/ download/pdf/Economic-Philosophic-Manuscripts-1844.pdf

Marx, K. (1973). Grundrisse: Outlines of the Critique of Political Economy. Translated by M. Nicolaus. New York, NY: Penguin Books.

Sellars, W. (1963). Science, Perception and Reality. London: Routledge and Kegan Paul.

Smith, A. P. (2013). A Non-Philosophical Theory of Nature: Ecologies of Thought. New York, NY: Palgrave Macmillan.

Sohn-Rethel, A. (1978). Intellectual and Manual Labor: Critique of Epistemology. London: Macmillan.
Conflict of Interest Statement: The author declares that the research was conducted in the absence of any commercial or financial relationships that could be construed as a potential conflict of interest.

Copyright (c) 2018 Kolozova. This is an open-access article distributed under the terms of the Creative Commons Attribution License (CC BY). The use, distribution or reproduction in other forums is permitted, provided the original author(s) and the copyright owner(s) are credited and that the original publication in this journal is cited, in accordance with accepted academic practice. No use, distribution or reproduction is permitted which does not comply with these terms. 